\title{
Measuring central coherence and set shifting in anorexia nervosa: the Navon Figures Task
}

\author{
Jenna Blumberg ${ }^{*}$, Karina Allen, Sue Byrne \\ From 2014 ANZAED Conference: Driven Bodies Driven Brains \\ Fremantle, Australia. 22-23 August 2014
}

People with eating disorders (EDs) are reported to have set-shifting difficulties, strengths in local or detailed information processing and weak central coherence or global processing. This study aimed to explore the validity of a novel, brief, global, neurocognitive task which has not previously been utilised in an ED population, the Navon Figures Task (NFT). The NFT is substantially quicker to administer than traditional neurocognitive tasks. Twenty women with anorexia nervosa (AN) and 20 healthy control women completed the Rey-Osterrieth Complex Figures Task (RCFT) to measure global/local processing strategies and completed the Wisconsin Card Sorting Test (WCT) to measure of set-shifting ability. The NFT was used as a measure of both set-shifting ability and central coherence. Consistent with previous findings, women with AN showed a tendency towards poorer performance on the RCFT and WCT than healthy control women. Scores on the NFT and RCFT were significantly, positively and strongly correlated in both the AN and healthy control samples, as were scores on the NFT and WCT. This indicates that the NFT has good concurrent validity with the other measures. These preliminary findings support the use of the NFT as a sensitive and practical measure in assessing central coherence and set-shifting abilities in EDs. Using measures like the NFT may potentially enhance our understanding of neurocognitive traits in AN and may help guide our treatment approaches to AN in the future.

This abstract was presented in the Assessment stream of the 2014 ANZAED Conference.
Published: 24 November 2014

doi:10.1186/2050-2974-2-S1-045

Cite this article as: Blumberg et al:: Measuring central coherence and set shifting in anorexia nervosa: the Navon Figures Task. Journal of Eating Disorders 2014 2(Suppl 1):045.

* Correspondence: 20880627@student.uwa.edu.au

The University of Western Australia, Perth, Australia

Submit your next manuscript to BioMed Central and take full advantage of:

- Convenient online submission

- Thorough peer review

- No space constraints or color figure charges

- Immediate publication on acceptance

- Inclusion in PubMed, CAS, Scopus and Google Scholar

- Research which is freely available for redistribution
( Biomed Central
C Biomed Central

(c) 2014 Blumberg et al; licensee BioMed Central Ltd. This is an Open Access article distributed under the terms of the Creative Commons Attribution License (http://creativecommons.org/licenses/by/4.0), which permits unrestricted use, distribution, and reproduction in any medium, provided the original work is properly cited. The Creative Commons Public Domain Dedication waiver (http://creativecommons.org/publicdomain/zero/1.0/) applies to the data made available in this article, unless otherwise stated. 